Victor Delpizzo Castagno ${ }^{1}$ Anaclaudia Gastal Fassa ${ }^{1}$

Manuel Augusto Pereira Vilela ${ }^{1}$

Rodrigo Dalke Meucci ${ }^{1}$

Deiner Paulo Martins Resende ${ }^{1}$

${ }^{1}$ Programa de Doutorado em Epidemiologia,

Departamento de Medicina Social, Universidade Federal de Pelotas. Av. Duque de Caxias 250, Fragata. 96001-970 Pelotas RS Brasil. vicastagno@hotmail.com

\title{
Moderate hyperopia prevalence and associated factors among elementary school students
}

\author{
Prevalência de hipermetropia e fatores associados \\ em escolares do ensino fundamental
}

Abstract Hyperopia is the most common refractive condition in childhood. There are few studies on moderate hyperopia and associated factors. This study aims to investigate the prevalence of moderate hyperopia and associated factors among school children. A cross-sectional study comprising 1,032 students attending 1st to 8th grades at two public schools was conducted in a Southern Brazilian urban area in 2012. Cycloplegia was used to examine both eyes and refractive error was measured through auto-refraction. A socioeconomic and cultural questionnaire was administered. Multivariable analysis was performed through Poisson regression. Moderate hyperopia prevalence was $13.4 \%$ (95\% CI, 11.2-15.4) and $85 \%$ of these did not wear glasses. Age was inversely associated with moderate hyperopia, while female gender $R P=1.39$ (95\%CI, $1.02-1.90)$ and white skin $R P=1.66$ (95\%CI, $1.04-2.66)$ were risk factors for this outcome. This study makes progress in estimating mild and moderate hyperopia prevalence both by age range and specific age. It emphasizes how the lack of this condition being corrected in southern Brazil is a serious problem. It highlights the importance of detailing and characterizing the amount of time spent on close-range, long-range and outdoor activities.

Key words Hyperopia, Prevalence, Children, Adolescent, Student
Resumo A hipermetropia é o estado refrativo mais comum na infância. Este estudo objetiva investigar a prevalência de hipermetropia moderada e fatores associados entre escolares, tendo em vista haver poucos estudos sobre o assunto. Métodos: Estudo transversal com 1.032 crianças do $1^{\circ}$ ao $8^{\circ}$ anos de duas escolas públicas da zona urbana de uma cidade do sul do Brasil, no período de abril a dezembro de 2012. Ambos os olhos foram cicloplegiados e o erro refrativo foi medido através de autorrefração. Foi aplicado questionário socioeconômico e cultural. A análise multivariada foi realizada utilizando a regressão de Poisson. Resultados: A prevalência de hipermetropia moderada foi de 13,4\% IC95\% (11,2\% - 15,4\%) e 85\% deles não usam óculos. Idade ficou inversamente associada com hipermetropia moderada enquanto sexo feminino $O R=1,39$ IC95\% $(1,02-1,90) e$ cor de pele branca $\mathrm{OR}=1,66$ IC95\% $(1,04-2,66)$ foram fatores de risco para o desfecho. Conclusão: Este estudo avança na estimativa de prevalência de hipermetropia leve e moderada por faixa etária e por idade especifica, enfatizando o grave problema da falta de correção no sul do Brasil. O estudo destaca a importância de detalhar e caracterizar a quantidade de tempo gasto em atividades de longe e de perto e ao ar livre.

Palavras chave Hipermetropia, Prevalência, Criança, Adolescente, Estudante 


\section{Introduction}

Hyperopia is the most common refractive condition in childhood ${ }^{1}$. Despite its association with accommodative esotropia and amblyopia, there is no consensus among eye care professionals on the cut-off point or the age at which correction should be prescribed ${ }^{2}$. The main concerns about treatment relate to how important hyperopia really is in the emmetropization process and the lack of evidence that correcting hyperopia in children can positively impact on school performance ${ }^{2,3}$. Moreover, more complete examinations such as those that evaluate the binocular and accommodative functions are neglected ${ }^{3,4}$. As a result there is lack of information about these disorders and their association with moderate hyperopia.

There is great variability in moderate hyperopia prevalence among children and adolescents in these studies, even among those using similar methodology, such as the studies that followed the Refractive Error Study in Children (RESC) proto$\mathrm{col}^{5}$. In the literature, moderate hyperopia prevalence ranged from $2.8 \%{ }^{6}$ to $28.9 \%{ }^{7}$ among 7 -yearold-children, $1.4 \%^{8}$ to $12.4 \%{ }^{7}$ among 10 -year-olds and $0.5 \%{ }^{9}$ to $10.3 \%{ }^{7}$ among those aged 15 . In the 5 -15 age group, moderate hyperopia prevalence ranged from $2.1 \%^{10}$ to $19.3 \%{ }^{11,12}$. There is no clear explanation for this age-specific variability. Although there are a significant number of studies on hyperopia prevalence, only a few have assessed factors associated with moderate hyperopia ${ }^{1}$.

According to the literature, hyperopia is inversely correlated to age $\mathrm{e}^{7-9,11-21}$ and is more common among White children ${ }^{1,22-24}$, whilst its association with gender ${ }^{6-10,12-16,18-23,25-32}$, parental education $^{1,6,9,25,27,33,34}$ and family income ${ }^{16,27,28}$ is inconclusive. With regard to environmental factors, a direct association has been found between spending more time engaged in outdoor activities and hyperopia in children, although literature on this aspect is very scarce ${ }^{1,35,36}$.

This study aims to investigate the prevalence of moderate hyperopia and associated factors among elementary school students.

\section{Methods}

A cross-sectional study was conducted involving all students attending the $1^{\text {st }}$ to $8^{\text {th }}$ grades at two public schools in the urban area of Pelotas, a medium-sized city in Rio Grande do Sul State (Southern Brazil) from April to December 2012.
According to the 2010 census, Pelotas has approximately 328,300 inhabitants, some 41,000 of whom are aged $0-14^{37}$.

The study population $(\mathrm{n}=1032)$ enabled moderate hyperopia prevalence to be estimated $(\geq+2.00 \mathrm{D})$, with a $95 \%$ significance level and an acceptable error of 2.2 percentage points, plus $10 \%$ to account for possible losses. Statistical power of $80 \%$ was obtained to detect prevalence ratios of 2.0 or higher with a $95 \%$ confidence level for this association, which showed an 'exposed/ unexposed' relationship of 2:1 and moderate hyperopia prevalence of $12 \%$ among the unexposed.

The study population was based on the lists of students provided by the schools. As the lists showed inconsistencies, visits and telephone contacts were made to identify students whose names were on the lists provided by the schools but were actually attending other schools. These students were excluded from the study. All students older than 16 present inappropriate grade for age, thus, to avoid selection bias they were also excluded.

The eye examinations and eye drop instillation were performed by two technicians supervised by an ophthalmologist in adapted rooms in the two schools. The socio-economic/demographic questionnaire was administered at the schools or at the students' homes by a trained interviewer to the person responsible for each student.Refractive measures were expressed in spherical equivalent (SE), calculated as the algebraic sum of the spherical measure plus half the cylindrical power ${ }^{5}$. SE for moderate hyperopia was: hyperopia $\mathrm{SE} \geq+2.00 \mathrm{D}$ (one or both eyes with no myopia, characterized as $\mathrm{SE} \leq 0.50 \mathrm{D})^{1,5}$. Hyperopia of $\geq+1.25$ was also considered. According to Rosner ${ }^{38}$, when this point is reached the use of correction should be started in order to avoid problems with school performance.

A 5 minute interval was left between the first and the second drop of cyclopentolate 1\%, being instilled. Direct photomotor reflex and pupil size were observed after a further 20 minute interval. A third drop was instilled into both eyes if pupils were photoreactive or their diameter was $\leq 6 \mathrm{~mm}$. Signs of pupillary dilation were checked once more after a further 15 minutes.

Auto-refraction with cycloplegia in both eyes was performed using a PRK-5000 auto-refractor (Potec Co. Ltd.). Auto-refractor calibration was measured at the beginning of each working day using a -5.25D model eye. Eight measurements were taken for each eye after aligning the student with the device. The eight measurements for each eye and their averages were printed. 
Other variables related to visual function were also collected during the study period. A third technician specialized in refraction and orthoptics therefore measured accommodative amplitude using the push-up technique performed in open space on $10 \%$ of the sample for the purposes of quality control. The Bland \& Altman $^{39}$ method was uses to assess agreement between the examiners' measurements and those of the technician responsible for quality control.

The demographic variables studied were: gender (male or female), age (in years) and skin color as observed by the interviewer (white, black, brown, yellow and indigenous). Age range was categorized as 6-8, 9-12 and 13-16 years, and skin color as white, black and other. Heredity was dichotomized whereby hyperopia was considered to have been inherited when both students' parents wore glasses and had started to wear them before they were 40 years old. Economic status was classified according to the criteria of the Brazilian Association of Research Companies $(\mathrm{ABEP})^{40}$. As information on the education of the head of household was not available in the study, maternal education was used instead.

Students' main activities when not at school were dichotomized (yes/no): watching TV, playing computer or video games, reading, playing outside and sports.

With regard to the appropriateness of age compared to school grade, 8 years of age or less was considered to be appropriate for the first grade, 9 years or less was considered to be appropriate for the second grade and so on successively for each grade. Age ranges outside those defined for each grade were considered to be inappropriate for the respective grade.

Analyses were performed using Stata (version 11.0). Crude analysis assessed associations using the chi-square test for heterogeneity. Adjusted analysis was performed using Poisson regression with robust variance and backward selection. The study's conceptual model guided the hierarchical analysis (Figure 1). Thus, demographic variables and heredity were the distal determinants evaluated; socioeconomic level was the intermediate determinant; and proximal determinants were the main activities engaged in by children and adolescents out of school and which were characterized as far (watching TV), near (reading, playing computer or video games), outdoor (playing outside) and sports activities (Figure 1). In order to control for confounding, variables showing a $\leq 0.20 \mathrm{p}$ value were kept in the model and $\leq 0.05$ $p$ values were considered statistically significant.

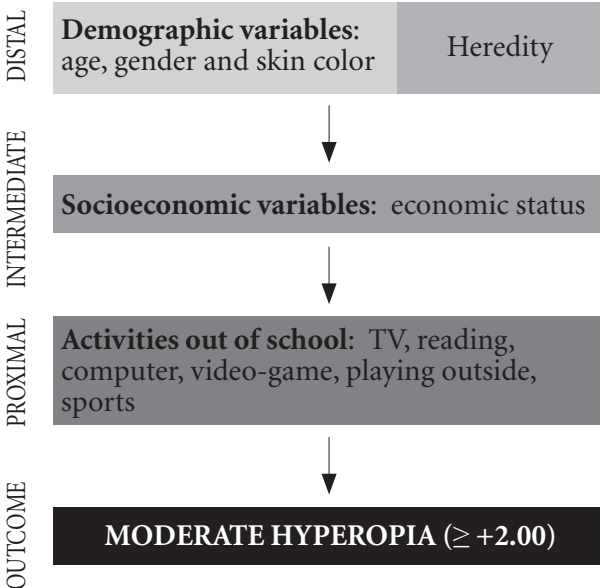

Figure 1. Conceptual framework that guided the hierarchical analysis.

The study was approved by the Ethics Committee of the Federal University of Pelotas (UFPel) School of Medicine and approved by the boards of both elementary schools. Study subjects and their parents had their right to refuse to take part and information confidentiality was guaranteed. Those who agreed to participate in the study underwent cycloplegic examinations and answered questionnaires only after parents and/or guardians had signed the informed consent form. Correction was prescribed for those cases needing it and those requiring ophthalmologic follow-up were treated at the UFPel School of Medicine Ophthalmology Clinic. The study was conducted in compliance with the ethical principles of the Declaration of Helsinki ${ }^{41}$, and National Health Council ${ }^{42}$.

\section{Results}

Of a total of 1,128 students from both schools, 1,032 underwent the cycloplegia examination followed by auto-refraction $(8.5 \%$ losses and refusals). After excluding 12 individuals older than 16 years, the study was comprised of 1,020 students aged 6 to 16 years old.

Average age was 10.6 years $(S D= \pm 2.7)$ and $55 \%$ of the students were boys. Regarding heredity, at least one of the parents of $28.1 \%$ of the students began wearing glasses before 40 years of age and $6 \%$ had both parents in this condition. Most of the studied students (58.5\%) belonged to eco- 
nomic level 'C', 79\% were White and only 15.5\% of the students practiced sports. When asked about the main activities the students engaged in out of school, $19 \%$ reported outdoor activities, $36 \%$ watching TV, $31 \%$ playing video or computer games, and 2\% reading. Half the children and adolescents studied were older than the expected age for their grade owing to having fallen behind in their academic performance (Table 1).

Moderate hyperopia prevalence was $13.4 \%$ (95\% CI, 11.2\%-15.4\%), while hyperopia $\geq$ $+1.25 \mathrm{D}$ prevalence was $34.0 \%$ (95\% CI, 31.1\%$36.9 \%)$. In the 6-7 and 12-13 age groups, moderate hyperopia prevalence was $21.7 \%$ (95\% CI, $15.2 \%-28.1 \%$ ) and $8.8 \%$ (95\% CI, 5.2\%-12.5\%), respectively (Table 2 ). Taking the students studied as a whole, hyperopic spherical equivalent was most common in all specific ages. $85 \%$ of students diagnosed as being moderately hyperopic did not wear glasses (Table 1).

Around $20 \%$ of children aged 6-7 years and $14 \%$ aged 9,10 and 11 years had moderate hyperopia. Moderate hyperopia prevalence was around 9\% among children and adolescents aged 12 or older (Table 2). The prevalence of hyperopia $\geq$ $+1.25 \mathrm{D}$ by specific age was more homogeneous. Prevalence was around $40 \%$ in those aged 6-11, decreasing to $28 \%$ at the age of 13 years and reaching $15 \%$ at 14 years (Table 2).

Examination of the crude analysis revealed no statistically significant association between moderate hyperopia and heredity, economic level, playing outside, playing sports, watching TV and playing computer or video games. Playing

Table 1. Description of the sample according to the following variables: demographic characteristics, heredity, economic status, children's activities, playing sports, wearing glasses, length of time children have being having eye care appointments, and appropriateness of school grade versus age. Pelotas-RS, Brazil, 2013.

\begin{tabular}{|c|c|c|}
\hline Variables & $\mathbf{N}$ & $\%$ \\
\hline \multicolumn{3}{|l|}{ Gender $(\mathrm{n}=1,020)$} \\
\hline Male & 564 & 55.3 \\
\hline Female & 456 & 44.7 \\
\hline \multicolumn{3}{|l|}{ Age $(\mathrm{n}=1.020)$} \\
\hline $13-16$ & 290 & 28.4 \\
\hline $9-12$ & 453 & 44.4 \\
\hline $6-8$ & 277 & 27.2 \\
\hline \multicolumn{3}{|l|}{ Skin color $(\mathrm{n}=1,020)$} \\
\hline Non-white & 215 & 21.0 \\
\hline White & 805 & 79.0 \\
\hline \multicolumn{3}{|l|}{ Heredity - wearing glasses $(n=988)^{* *}$} \\
\hline $\begin{array}{l}\text { Neither parents wear glasses / one does not wear glasses and the other started wearing } \\
\text { them after } 40 \text { years old / both started wearing after } 40 \text { years old }\end{array}$ & 650 & 65.8 \\
\hline One of the parents wearing glasses before 40 years old & 278 & 28.1 \\
\hline Both parents wearing glasses before 40 years old & 60 & 6.1 \\
\hline \multicolumn{3}{|l|}{ Economic status $(\mathrm{ABEP})^{\Omega}(\mathrm{n}=984)^{* * *}$} \\
\hline $\mathrm{A}+\mathrm{B}$ & 351 & 35.7 \\
\hline $\mathrm{C}$ & 574 & 58.3 \\
\hline $\mathrm{D}+\mathrm{E}$ & 59 & 6.0 \\
\hline Plays outside ${ }^{\mathfrak{E}}$ (yes) & 190 & 19.0 \\
\hline Play sports ${ }^{\varepsilon}$ (yes) & 155 & 15.5 \\
\hline Watches $\mathrm{TV}^{\mathfrak{\varepsilon}}$ (yes) & 358 & 35.8 \\
\hline Plays computer or video games ${ }^{\mathfrak{\varepsilon}}$ (yes) & 309 & 30.9 \\
\hline $\operatorname{Reads}^{\mathfrak{E}}$ (yes) & 20 & 2.0 \\
\hline Grade versus age appropriateness $^{\epsilon}(\mathrm{n}=1.008)$ (appropriate) & 508 & 50.4 \\
\hline Moderate hyperopic $(\mathrm{n}=137)$ NOT wearing glasses & 117 & 85.4 \\
\hline
\end{tabular}

** 32 parents/guardians had no knowledge of or could not recall using eye correction for themselves or for their spouse (when only one of the parents answered the questionnaire) or had no knowledge of or could not recall the child's parents using of correction (when another relative/guardian answered the questionnaire). ${ }^{\Omega}$ Brazilian Association of Research Companies. ${ }^{* * *} 36$ parents/ guardians had no knowledge of or refused to provide information on the education of the child’s mother. $\mathrm{N}={ }^{£} 999 .{ }^{£} 12$ children had no information provided as to their grade on the lists made available by the schools. 
outside $(\mathrm{p}=0.106)$ and watching TV $(\mathrm{p}=0.087)$ were kept in the model in order to control for confounding (Table 3 ).

Table 2. Age-specific hyperopia prevalence.

\begin{tabular}{lcc}
\hline Age $(\mathbf{N})$ & $\begin{array}{c}\geq+2.00 D \\
\text { Prevalence \% } \\
(\mathbf{9 5 \%} \text { CI })\end{array}$ & $\begin{array}{c}\geq+\mathbf{1 . 2 5} \\
\text { Prevalence \% } \\
(\mathbf{9 5 \%} \text { CI })\end{array}$ \\
\hline $6(69)$ & $23.1(12.9-33.4)$ & $43.4(31.4-55.4)$ \\
$7(92)$ & $20.6(12.2-29.0)$ & $48.9(38.5-59.3)$ \\
$8(116)$ & $17.2(10.2-24.2)$ & $46.5(37.3-55.7)$ \\
$9(112)$ & $13.3(6.9-19.7)$ & $34.8(25.8-43.7)$ \\
$10(113)$ & $14.1(7.6-20.0)$ & $38.9(29.8-48.0)$ \\
$11(114)$ & $14.9(8.2-21.5)$ & $40.3(31.2-49.4)$ \\
$12(114)$ & $8.7(3.4-14.0)$ & $28.0(19.6-36.4)$ \\
$13(123)$ & $8.9(3.8-14.0)$ & $22.7(15.2-30.2)$ \\
$14(102)$ & $5.8(1.2-10.5)$ & $14.7(7.7-21.6)$ \\
15 & - & - \\
$16^{*}$ & - & -
\end{tabular}

N Sample size, D diopters, CI confidence interval. * Specific ages with insufficient $\mathrm{N}$.
Examination of the association between moderate hyperopia and independent variables showed, after adjustment for confounding factors, that girls were $39 \%$ more hyperopic than boys $\mathrm{RP}=1.41(95 \% \mathrm{CI}, 1.02-1.90)$ and White were $66 \%$ more hyperopic than Black RP = 1.66(95\% CI, 1.04-2.66). Age had an inverse association with hyperopia $(\mathrm{p}<0.001)$. Those aged 6-8 were twice as likely to be hyperopic than those aged 13-16 RP $=2.37(95 \% \mathrm{CI}, 1.51-3.72$ ) (Table 4). Socioeconomic status, heredity and the variables relating to the students' main activities out of school were not significantly associated with the outcome $(\mathrm{p}>0.05)$.

The mean difference between the readings obtained by examiners and the gold standard with regard to the measurement of accommodative amplitude for quality control using the Bland-Altman method was 1.0D (95\% CI, 0.57D-1.45D) and the agreement between the examiners' measurements and the gold standard regarding accommodative insufficiency when using the kappa statistic was 1.0.

Table 3. Moderate hyperopia $(\geq+2.00 \mathrm{D} \mathrm{D})$ : prevalence and crude analysis of associated factors. Pelotas, RS, Brazil, 2013. $(\mathrm{n}=1020)$.

\begin{tabular}{|c|c|c|c|}
\hline Variables & $\%$ & $\begin{array}{c}\text { Crude } \\
\text { PR CI (95\%) }\end{array}$ & p-Value \\
\hline Heredity - wearing glasses $(\mathrm{n}=988)^{*}$ & & & 0.234 \\
\hline $\begin{array}{l}\text { Neither parents wear glasses / one does not wear glasses and } \\
\text { the other started wearing them after } 40 \text { years old / both started } \\
\text { wearing after } 40 \text { years old }\end{array}$ & 14.6 & 1.00 & \\
\hline One of the parents wearing glasses before 40 years old & 12.5 & $0.86(0.60-1.23)$ & \\
\hline Both parents wearing glasses before 40 years old & 10.0 & $0.68(0.31-1.49)$ & \\
\hline Economic status $(\mathrm{ABEP})^{\Omega}(\mathrm{n}=984)^{* *}$ & & & 0.822 \\
\hline $\mathrm{A}+\mathrm{B}$ & 13.1 & 1.00 & \\
\hline $\mathrm{C}$ & 14.5 & $1.10(0.78-1.54)$ & \\
\hline $\mathrm{D}+\mathrm{E}$ & 11.9 & $0.90(0.42-1.90)$ & \\
\hline Plays outside ${ }^{\epsilon}$ & & & 0.106 \\
\hline No & 14.6 & 1.00 & \\
\hline Yes & 10.0 & $0.68(0.43-1.08)$ & \\
\hline Play sports $\epsilon^{\epsilon}$ & & & 0.948 \\
\hline No & 13.7 & 1.00 & \\
\hline Yes & 13.5 & $0.98(0.63-1.51)$ & \\
\hline Watches $\mathrm{TV}^{€}$ & & & 0.087 \\
\hline No & 12.3 & 1.00 & \\
\hline Yes & 16.2 & $1.31(0.96-1.79)$ & \\
\hline Computer or video games ${ }^{\epsilon}$ & & & 0.209 \\
\hline Yes & 11.5 & 1.00 & \\
\hline No & 14.6 & $1.25(0.87-1.75)$ & \\
\hline
\end{tabular}

PR prevalence ratio; CI confidence interval. * 32 parents/guardians had no knowledge of or could not recall using eye correction for themselves or for their spouse (when only one of the parents answered the questionnaire) or had no knowledge of or could not recall the child's parents using of correction (when another relative/guardian answered the questionnaire). ${ }^{\Omega}$ Brazilian Association of Research Companies. ${ }^{* *} 36$ parents/guardians had no knowledge of or refused to provide information on the education of the child's mother. ${ }^{\epsilon} \mathrm{n}=999$.

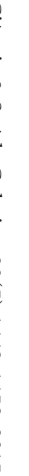




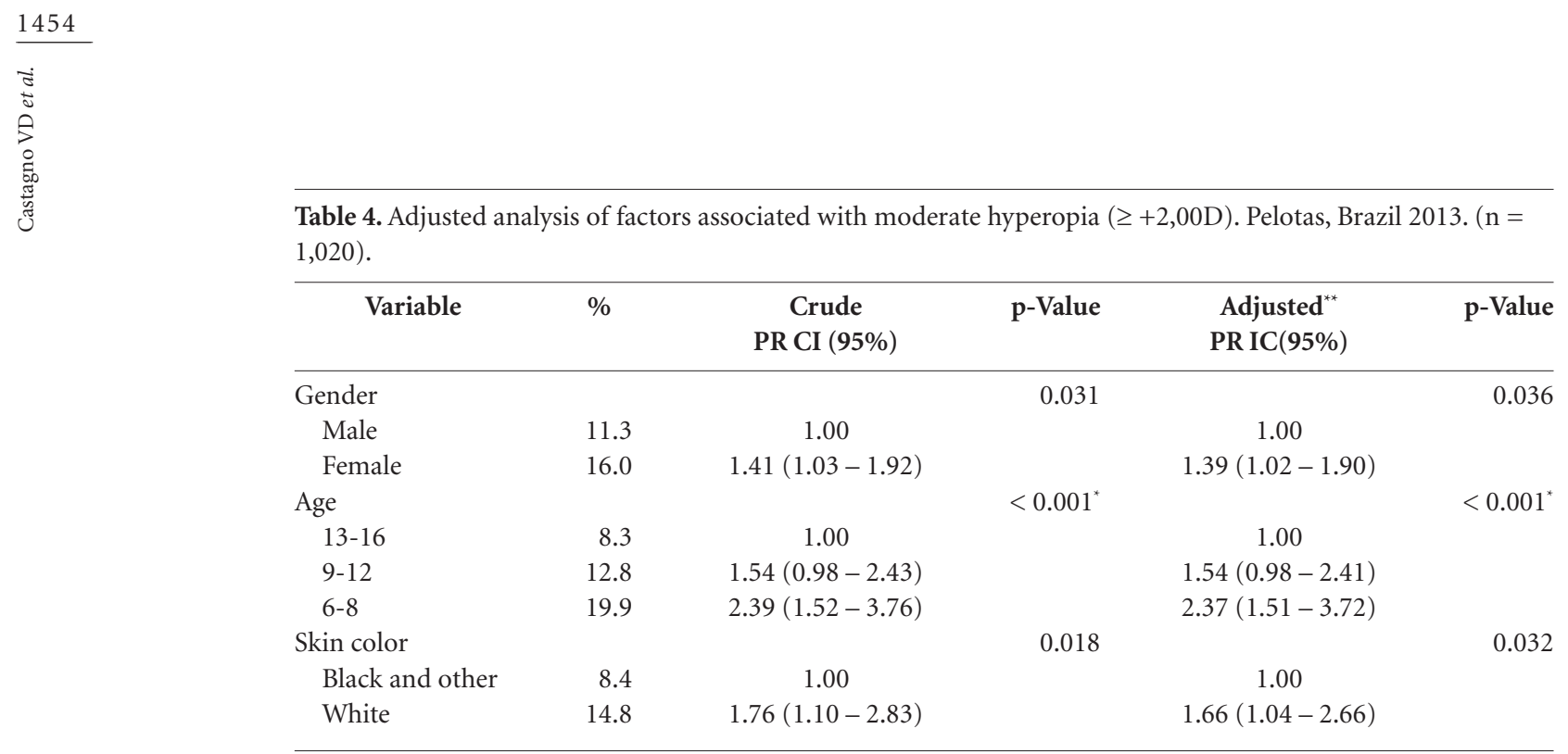

PR prevalence ratio, CI confidence interval, D dioptries. * test for linear trend. ** adjusted analysis for variables of the same level.

\section{Discussion}

Almost one fifth of the school population was diagnosed as having moderate hyperopia $(\geq$ +2.00D SE) and more than three-quarters of these did not use correction and half the children and adolescents were older than expected for the school grade they were attending. Age was inversely associated with moderate hyperopia, while female sex and white skin color were directly associated. Heredity, economic level, playing outside, playing sports, watching TV, playing computer or video games and reading were not associated with moderate hyperopia.

This study was conducted in two schools in the same neighborhood, with strong representation of lower-middle income families and therefore not representative of different economic levels. On the other hand, the study evaluated refractive error in students objectively through auto-refraction. The low percentage of losses and refusals reinforces the validity of the findings. Although there is an overestimation of the amount of refractive errors using an auto-refractor in comparison with retinoscopy, the difference between the two test methods is not significant in the determination of refractive errors ${ }^{5}$. The instillation of cycloplegic drops followed the protocol used in the major population-based studies on refractive errors, and cycloplegia precision control was performed by observing direct photomotor reflection and pupil size in each eye before auto-refraction ${ }^{5}$. The cut-off point for moderate hyperopia $(\mathrm{SE} \geq+2.00 \mathrm{D})$ also followed the RESC protocol, thus enabling consistency with other studies to be evaluated.
There is little evidence to support the definition of the ideal cut-off point for starting hyperopia correction. Some authors do not recommend the prescription of correction for young children because it decreases the stimulus (hyperopic defocus) which regulates the growth of the eye and the interactions between the ocular components during the emmetropization period. Other authors emphasize that the emmetropization period occurs very quickly, centering on the first year of life, and that the role of hyperopic defocus is not clear as the main agent in stimulating emmetropization during childhood ${ }^{2}$. Also, there is controversy about the need to take into account the binocular and accommodative functions in defining hyperopia correction. However, Rosner showed that hyperopic children with refractive errors greater than $+1.25 \mathrm{D}$ without correction had worse school performance ${ }^{4,38,43}$ suggesting that the lack of correction in children with moderate hyperopia, as found in this study, is a serious problem.

The prevalence of moderate hyperopia among children and adolescents aged 6-16 years was higher than that observed in most other studies using the same age range $e^{4,17-23}$. Prevalence was similar to the $16.6 \%$ (95\% CI, $13.6 \%-19.7 \%$ ) found in Iran, lower than the 19\% found in Chile and in another study conducted in $\operatorname{Iran}^{11,12}$. With regard to other age ranges, the $26 \%$ (95\% CI, $20 \%-33 \%$ ) prevalence of moderate hyperopia found in Northern Ireland ${ }^{20}$ and the 12.3\% (95\% CI, 8.8\%-15.7\%) found in England ${ }^{34}$ in children aged 6-7 is within the estimated prevalence confidence interval in this study. Among children and adolescents aged 12-13, the prevalence of moder- 
ate hyperopia was also similar to the 5.4\% (95\% CI, 2.8-8.0) found in England ${ }^{34}$.

Regarding moderate hyperopia prevalence by specific age, in a study conducted in Australia Ip et al. found $13.2 \%$ (95\% CI, 11.1-15.2) in children aged 6 years and 5.0\% (95\% CI, 4.1\%-5.8\%) in those aged $12^{1}$. These findings are consistent with our study. Moderate hyperopia prevalence in the 7-11 specific age group was similar to that found in the population-based study conducted by Fotouhi in Dezful, Iran, with 5,544 students and a $96.8 \%$ response rate ${ }^{7}$.

In agreement with most studies in the literature, age was inversely associated with moderate hyperopia ${ }^{7,9,11-13,15,17,18,21,27,44}$. The process of emmetropization and eye growth stimulated by hyperopic defocus is minimal after 3 years of age, which mitigates the variability of hyperopic error $^{2}$. Nevertheless, there is evidence that the axial length of the eye continues to increase until the age of 12 to 14 years, suggesting a decrease in the hyperopic spherical equivalent as age increases ${ }^{45}$.

In this study girls were more hyperopic than boys. This finding is consistent with the risk of between $20 \%$ and $50 \%$ reported by some articles $^{10,11,13}$. However, most studies showed no significant association between gender and moderate hyperopia among children and adolescents aged 5-17-9,12,15,18,20-22,26,29-31. With regard to ocular components, on average girls' eyes have lower axial length when compared to boys ${ }^{19,22,45-48}$, thus increasing their chance of being hyperopic. Differences in the association between gender and far and near activities in different cultures may affect the association between gender and hyperopia $^{36}$. Furthermore, although genders are well represented in the literature, they may have selection bias, whether because of the greater difficulty girls face in accessing schools in some cultures, or because of their being more willing to participate in health studies.

White students showed higher moderate hyperopia prevalence than non-white students. This result agrees with a study conducted in England with children aged 6-7 years ${ }^{34}$ and Kleinstein et al.'s study in the United States with children and adolescents aged 5-17 years, using a hyperopia cut-off point greater than or equal to $+1.25 \mathrm{D}^{23}$. With regard to ocular components, White children and adolescents can be expected to present higher moderate hyperopia prevalence than Black ones because the axial length of their eyes is less than that of Black children and adolescents $^{49}$. Moreover, differences in economic status, cultural aspects and far and near activities also impact the association between skin color and moderate hyperopia.

Population-based studies have observed high hyperopia prevalence rates among members of the same family (familial aggregation) $)^{35,50}$ as well as increased correlation between high hyperopia and monozygotic twins when compared to dizygotic twins, suggesting a strong genetic component ${ }^{3,51}$. In this study, the fact that parents wore glasses before the 40 years of age was not associated with moderate hyperopia in their children, although a limitation was that parents' refractive error type was not defined precisely.

There was no association between outdoor activities (sports and playing outside) and moderate hyperopia. Literature shows that children and adolescents who spend more hours per week engaged in outdoor activities (including sports) are more hyperopic than those who spend less time doing these activities ${ }^{1,35,36}$. Outdoor activities do not require much accommodation and therefore stimulate axial length less ${ }^{49,52}$. The greater intensity of the light in outside environments causes reflexive miosis, thus increasing focus depth and image sharpness ${ }^{36}$. Light also stimulates dopamine release, thus inhibiting ocular growth ${ }^{36,50}$.

There is no consensus on classifying 'watching TV' in terms of distance. Some studies consider it to be intermediate, others have classified it as near ${ }^{1,53}$, while the present study considered it to be far, based on the hypothesis that watching TV may be a risk factor for moderate hyperopia. In keeping with the literature, no association was found between watching TV and moderate hyperopia.

No association was found between near activities (reading and playing computer and video games) and moderate hyperopia. According to the literature, children who spend more hours per week engaging in near activities such as doing homework, studying, reading for pleasure, playing a musical instrument and using the computer are less hyperopic when compared to those who spend fewer hours per week performing these activities $^{35,53}$. The study conducted by Rose in Australia showed a modifying effect of ethnicity, since Caucasian children tended to be less hyperopic the more they increased the time spent doing near activities, whilst this association was not observed among children of Asian origin ${ }^{36}$. Near activities place greater demands on the accommodative and binocular processes to keep images sharp ${ }^{2}$.

One study has shown that the time devoted to console games is a risk factor for hyperopia in children ${ }^{35}$. Our study found no association 
between playing computer or video games and moderate hyperopia. The association examined included activities involving different degrees of visual effort, whereby using a computer was considered to be a much nearer activity than playing video games.

This study has made progress in estimating the prevalence of mild and moderate hyperopia both by age range and specific age, emphasizing the serious problem of the lack of this condition being corrected in Southern Brazil. It also indicates the inverse association between age and hyperopia, as well as the positive association between hyperopia and female gender and white skin color. Future studies should further examine genetic factors related to moderate hyperopia, with improved evaluation of parental refractive errors. The evaluation of far, near and outdoor activities is still scarce in the literature and there is no consensus on their classification. It is important for far, near and outdoor activities to be detailed, as well as to characterize the time devoted to each activity and accurately separate activities requiring different degrees of visual effort. There is significant variability in moderate hyperopia prevalence between the different studies. Researchers need to reflect on whether the causal chain that is being examined comprises this variability or if there are other aspects that should be evaluated, such as nutritional factors, for example.

\section{Collaborations}

VD Castagno prepared the project, carried out the work field, analyzed the data and wrote the article. AG Fassa developed the project, held the field work, analyzed the data and wrote the article. MAP Vilela contributed to interpretation data and the review of the article writing. $\mathrm{RD}$ Meucci developed the project, carried out the work field, analyzed the data and wrote the article. DPM Resende contributed to the interpretation of data the review of the article writing.

\section{Acknowledgements}

This systematic review has been funded by the Brazilian Federal Agency for the Support and Evaluation of Graduate Education (CAPES), part of the Brazilian Ministry of Education. 


\section{References}

1. Ip JM, Robaei D, Kifley A, Wang JJ, Rose KA, Mitchell P. Prevalence of hyperopia and associations with eye findings in 6- and 12-year-olds. Ophthalmology 2008; 115(4):678-685.

2. Mutti DO. To emmetropize or not to emmetropize? The question for hyperopic development. Optom Vis Sci 2007; 84(2):97-102.

3. Tarczy-Hornoch K. The epidemiology of early childhood hyperopia. Optom Vis Sci 2007; 84(2):115-123.

4. Rosner J. The still neglected hyperope. Optom Vis Sci 2004; 81(4):223-224.

5. Negrel AD, Maul E, Pokharel GP, Zhao J, Ellwein LB. Refractive Error Study in Children: sampling and measurement methods for a multi-country survey. Am J Ophthalmol 2000; 129(4):421-426.

6. Naidoo KS, Raghunandan A, Mashige KP, Govender P, Holden BA, Pokharel GP, Ellwein LB. Refractive error and visual impairment in African children in South Africa. Invest Ophthalmol Vis Sci 2003; 44(9):3764-3770.

7. Fotouhi A, Hashemi H, Khabazkhoob M, Mohammad K. The prevalence of refractive errors among schoolchildren in Dezful, Iran. Br J Ophthalmol 2007; 91(3):287-292.

8. Goh PP, Abqariyah Y, Pokharel GP, Ellwein LB. Refractive error and visual impairment in school-age children in Gombak District, Malaysia. Ophthalmology 2005; 112(4):678-685.

9. He M, Zeng J, Liu Y, Xu J, Pokharel GP, Ellwein LB. Refractive error and visual impairment in urban children in southern china. Invest Ophthalmol Vis Sci 2004; 45(3):793-799.

10. Pokharel GP, Negrel AD, Munoz SR, Ellwein LB. Refractive Error Study in Children: results from Mechi Zone, Nepal. Am J Ophthalmol 2000; 129(4):436-444.

11. Maul E, Barroso S, Munoz SR, Sperduto RD, Ellwein LB. Refractive Error Study in Children: results from La Florida, Chile. Am J Ophthalmol 2000; 129(4):445-454.

12. Ostadimoghaddam H, Fotouhi A, Hashemi H, Yekta A, Heravian J, Rezvan F, Khabazkhoob M. Prevalence of the refractive errors by age and gender: the Mashhad eye study of Iran. Clin Experiment Ophthalmol 2011; 39(8):743-751.

13. Zhao J, Pan X, Sui R, Munoz SR, Sperduto RD, Ellwein LB. Refractive Error Study in Children: results from Shunyi District, China. Am J Ophthalmol 2000; 129(4):427-435.

14. Hashemi H, Fotouhi A, Mohammad K. The age- and gender-specific prevalences of refractive errors in Tehran: the Tehran Eye Study. Ophthalmic Epidemiol 2004; 11(3):213-225.

15. Pi LH, Chen L, Liu Q, Ke N, Fang J, Zhang S, Xiao J, Ye WJ, Xiong Y, Shi H, Yin ZQ. Refractive status and prevalence of refractive errors in suburban school-age children. Int J Med Sci 2010; 7(6):342-353.

16. Dandona R, Dandona L, Srinivas M, Giridhar P, McCarty CA, Rao GN. Population-based assessment of refractive error in India: the Andhra Pradesh eye disease study. Clin Experiment Ophthalmol 2002; 30(2):84-93.

17. Laatikainen L, Erkkila H. Refractive errors and other ocular findings in school children. Acta Ophthalmol (Copenh) 1980; 58(1):129-136.
18. Yekta A, Fotouhi A, Hashemi H, Dehghani C, Ostadimoghaddam H, Heravian J, Derakhshan A, Yekta R, Behnia M, Khabazkhoob M. Prevalence of refractive errors among schoolchildren in Shiraz, Iran. Clin Experiment Ophthalmol 2010; 38(3):242-248.

19. Zadnik K, Manny RE, Yu JA, Mitchell GL, Cotter SA, Quiralte JC, Shipp M, Friedman NE, Kleinstein R, Walker TW, Jones LA, Moeschberger ML, Mutti DO; Collaborative Longitudinal Evaluation of Ethnicity and Refractive Error (CLEERE) Study Group. Ocular component data in schoolchildren as a function of age and gender. Optom Vis Sci 2003; 80(3):226-236.

20. O’Donoghue L, McClelland JF, Logan NS, Rudnicka AR, Owen CG, Saunders KJ. Refractive error and visual impairment in school children in Northern Ireland. $\mathrm{Br}$ J Ophthalmol 2010; 94(9):1155-1159.

21. Rezvan F, Khabazkhoob M, Fotouhi A, Hashemi H, Ostadimoghaddam H, Heravian J, Azizi E, Khorasani AA, Yekta AA. Prevalence of refractive errors among school children in Northeastern Iran. Ophthalmic Physiol Opt 2012; 32(1):25-30.

22. Ip JM, Huynh SC, Robaei D, Kifley A, Rose KA, Morgan IG, Wang JJ, Mitchell P. Ethnic differences in refraction and ocular biometry in a population-based sample of 11-15-year-old Australian children. Eye 2008; 22(5):649-656.

23. Kleinstein RN, Jones LA, Hullett S, Kwon S, Lee RJ, Friedman NE, Manny RE, Mutti DO, Yu JA, Zadnik K; Collaborative Longitudinal Evaluation of Ethnicity and Refractive Error Study Group. Refractive error and ethnicity in children. Arch Ophthalmol 2003; 121(8):11411147.

24. Giordano L, Friedman DS, Repka MX, Katz J, Ibironke J, Hawes P, Tielsch JM. Prevalence of refractive error among preschool children in an urban population: the Baltimore Pediatric Eye Disease Study. Ophthalmology 2009; 116(4):739-746.

25. Murthy GV, Gupta SK, Ellwein LB, Munoz SR, Pokharel GP, Sanga L, Bachani D. Refractive error in children in an urban population in New Delhi. Invest Ophthalmol Vis Sci 2002; 43(3):623-631.

26. Gronlund MA, Andersson S, Aring E, Hard AL, Hellstrom A. Ophthalmological findings in a sample of Swedish children aged 4-15 years. Acta Ophthalmol Scand 2006; 84(2):169-176.

27. Dandona R, Dandona L, Srinivas M, Sahare P, Narsaiah S, Munoz SR, Pokharel GP, Ellwein LB. Refractive error in children in a rural population in India. Invest Ophthalmol Vis Sci 2002; 43(3):615-622.

28. Dandona R, Dandona L, Naduvilath TJ, Srinivas M, McCarty CA, Rao GN. Refractive errors in an urban population in Southern India: the Andhra Pradesh Eye Disease Study. Invest Ophthalmol Vis Sci 1999; 40(12):2810-2818.

29. Casson RJ, Kahawita S, Kong A, Muecke J, Sisaleumsak S, Visonnavong V. Exceptionally Low Prevalence of Refractive Error and Visual Impairment in Schoolchildren from Lao People's Democratic Republic. Ophthalmology 2012; 119(10):2021-2027. 
30. Uzma N, Kumar BS, Khaja Mohinuddin Salar BM, Zafar MA, Reddy VD. A comparative clinical survey of the prevalence of refractive errors and eye diseases in urban and rural school children. Can J Ophthalmol 2009; 44(3):328-333.

31. Gao Z, Meng N, Muecke J, Chan WO, Piseth H, Kong A, Jnguyenphamhh T, Dehghan Y, Selva D, Casson R, Ang K. Refractive error in school children in an urban and rural setting in Cambodia. Ophthalmic Epidemiol 2012; 19(1):16-22

32. Niroula DR, Saha CG. Study on the refractive errors of school going children of Pokhara city in Nepal. Kathmandu Univ Med J (KUMJ) 2009; 7(25):67-72.

33. Saw SM, Goh PP, Cheng A, Shankar A, Tan DT, Ellwein LB. Ethnicity-specific prevalences of refractive errors vary in Asian children in neighbouring Malaysia and Singapore. Br J Ophthalmol 2006; 90(10):1230-1235.

34. Logan NS, Shah P, Rudnicka AR, Gilmartin B, Owen CG. Childhood ethnic differences in ametropia and ocular biometry: the Aston Eye Study. Ophthalmic Physiol Opt 2011; 31(5):550-558.

35. Ip JM, Saw SM, Rose KA, Morgan IG, Kifley A, Wang JJ, Mitchell P. Role of near work in myopia: findings in a sample of Australian school children. Invest Ophthalmol Vis Sci 2008; 49(7):2903-2910.

36. Rose KA, Morgan IG, Ip J, Kifley A, Huynh S, Smith W, Mitchell P. Outdoor activity reduces the prevalence of myopia in children. Ophthalmology 2008; 115(8):12791285.

37. Instituto Brasileiro de Geografia e Estatística (IBGE). Censo nacional de 2010 [internet]. [cited 2012 Oct 12]. Available from: http//censo2010.ibge.gov.br/apps/ atlas/

38. Rosner J. The relationship between moderate hyperopia and academic achievement: how much plus is enough? J Am Optom Assoc 1997; 68(10):648-650.

39. Bland JM, Altman DG. Statistical methods for assessing agreement between two methods of clinical measurement. Lancet 1986; 1(8476):307-310.

40. Associação Brasileira de Empresas de Pesquisa (ABEP). Critério de Classificação Econômica Brasil. São Paulo: ABEP; 2012.

41. World Medical Association (WMA). World Medical Association Declaration of Helsinki. Tóquio: WMA; 2004.

42. Brasil. Ministério da Saúde (MS). Conselho Nacional de Saúde. Resolução n466, de 12 de dezembro de 2012. Diário Oficial da União 2013; 13 jun.

43. Rosner J. Relation between tonic accommodation and visual perceptual skills development in 6- to 12-yearold children. Optom Vis Sci 1989; 66(8):526-529.

44. Hashemi H, Iribarren R, Morgan IG, Khabazkhoob M, Mohammad K, Fotouhi A. Increased hyperopia with ageing based on cycloplegic refractions in adults: the Tehran Eye Study. Br J Ophthalmol 2010; 94(1):20-23.
45. Larsen JS. The sagittal growth of the eye. IV. Ultrasonic measurement of the axial length of the eye from birth to puberty. Acta Ophthalmol (Copenh) 1971;49(6):873886 .

46. Ojaimi E, Rose KA, Morgan IG, Smith W, Martin FJ, Kifley A, Robaei D, Mitchell P. Distribution of ocular biometric parameters and refraction in a population-based study of Australian children. Invest Ophthalmol Vis Sci 2005; 46(8):2748-2754.

47. Lin LL, Shih YF, Tsai CB, Chen CJ, Lee LA, Hung PT, Hou PK. Epidemiologic study of ocular refraction among schoolchildren in Taiwan in 1995. Optom Vis Sci 1999; 76(5):275-281.

48. Twelker JD, Mitchell GL, Messer DH, Bhakta R, Jones LA, Mutti DO, Cotter SA, Klenstein RN, Manny RE, Zadnik K; CLEERE Study Group. Children's Ocular Components and Age, Gender, and Ethnicity. Optom Vis Sci 2009; 86(8):918-935.

49. Trivedi RH, Wilson ME. Biometry data from caucasian and african-american cataractous pediatric eyes. Invest Ophthalmol Vis Sci 2007; 48(10):4671-4678.

50. McCarthy CS, Megaw P, Devadas M, Morgan IG. Dopaminergic agents affect the ability of brief periods of normal vision to prevent form-deprivation myopia. Exp Eye Res 2007; 84(1):100-107.

51. Teikari J, Koskenvuo M, Kaprio J, O’Donnell J. Study of gene-environment effects on development of hyperopia: a study of 191 adult twin pairs from the Finnish Twin Cohort Study. Acta geneticae medicae et gemellologiae 1990; 39(1):133-136.

52. Wallman J, Winawer J. Homeostasis of eye growth and the question of myopia. Neuron 2004; 43(4):447-468.

53. Mutti DO, Mitchell GL, Moeschberger ML, Jones LA, Zadnik K. Parental myopia, near work, school achievement, and children's refractive error. Invest Ophthalmol Vis Sci 2002; 43(12):3633-3640.

Article submitted 03/22/2014

Approved 11/14/2014

Final version submitted 11/16/2014 